\title{
O USO SOCIAL DAS TECNOLOGIAS DE COMUNICAÇÃO PELO SURDO: LIMITES E POSSIBILIDADES PARA O DESENVOLVIMENTO DA LINGUAGEM
}

\section{THE SOCIAL USE OF COMMUNICATION TECHNOLOGIES BY THE DEAF: LIMITS AND POSSIBILITIES FOR THE DEVELOPMENT OF THE LANGUAGE}

\author{
Clélia Maria Ignatius Nogueira ${ }^{1}$ \\ Marília Ignatius Nogueira Carneiro ${ }^{2}$ \\ Tânia dos Santos Alvarez da Silva ${ }^{3}$
}

\begin{abstract}
Resumo: Desde a década de 1990 os surdos vivenciam uma intensa transformação em sua vida social, em função da naturalização da comunicação digital, e educacional, com a mudança de paradigma do oralismo para o bilinguismo. Este artigo apresenta resultados de investigação realizada em três etapas com dez sujeitos surdos, buscando identificar a) a importância atribuída por eles à escrita e a competência na utilização da comunicação digital; b) sua percepção acerca dos equívocos cometidos em suas produções escritas e c) sua competência na interpretação de textos para identificar os limites e as possibilidades de desenvolvimento da língua escrita, pelo uso social das tecnologias de comunicação pelos surdos. Os resultados apontaram a ressignificação do sentido social da escrita do Português para os surdos proporcionada pela comunicação digital, o que poderia ser explorado pela escola.
\end{abstract}

Palavras-Chave: Educação de surdos; Comunicação digital; Língua Portuguesa escrita.

\begin{abstract}
From the 1990s the deaf experience an intense transformation in their social life, due to the naturalization of digital and educational communication, with the paradigm shift from oralism to bilingualism. This article presents research carried out through three moments with ten deaf individuals, seeking to identify : a) the importance they attributed to writing and their competence in the use of digital communication; b) their perception about the mistakes made in their written productions and c) their competence in the interpretation of texts and thus identify the limits and possibilities for the development of written language, the social use of communication technologies by the deaf. The results pointed out the re-signification of their social sense of the Portuguese writing for the deaf, provided by the digital communication which could be explored by the school.
\end{abstract}

Keywords: Education of the deaf; Digital communication; Written Portuguese language.

\footnotetext{
${ }^{1}$ Doutora em Educação pela Universidade Estadual Paulista (UNESP). Docente do Programa de PósGraduação em Educação em Ciências e em Educação Matemática da Universidade Estadual do Oeste do Paraná (PPGECEM/UNIOESTE), Cascavel, Paraná, Brasil. E-mail: voclelia@ gmail.com

${ }^{2}$ Mestre em Educação pela Universidade Estadual de Maringá (UEM). Doutoranda do Programa de PósGraduação em Educação Escolar da Universidade Estadual Paulista (UNESP). Docente da Universidade Estadual de Maringá (UEM), Maringá, Paraná, Brasil. E-mail: mariliain@ hotmail.com

${ }^{3}$ Doutora em Educação pela Universidade Federal do Paraná (UFPR). Docente do Programa de Pósgraduação em Educação da Universidade Estadual de Maringá (PPE/UEM), Maringá, Paraná, Brasil. Email: tsasilva@uol.com.br
} 


\section{Introdução}

Desde a segunda metade da década de 1990 as pessoas surdas vivenciam um período intenso de transformações que teve início com a mudança de paradigma em sua educação - do oralismo ao bilinguismo ${ }^{4}$ - e continua em função do desenvolvimento tecnológico que lhes proporcionou novas possibilidades de comunicação e de acesso à informação.

No âmbito educacional, as transformações aconteceram, particularmente porque mudou a concepção de surdez, que passou de patologia, deficiência ou anormalidade, como acreditavam os oralistas, para diferença linguística ou experiência visual como preconiza o bilinguismo.

Após mais de um século de predomínio do oralismo, o movimento mundial de mudança de paradigma educacional começa já na década de 1960, após estudos do pesquisador norte-americano William Stokoe que conferiram status linguístico às línguas de sinais.

No Brasil, a adoção do bilinguismo como filosofia educacional começa a se delinear com a publicação da Política Nacional de Educação Especial (PNEE) (BRASIL, 1994), na qual, aparece pela primeira vez, de forma explícita em um documento oficial brasileiro, a discussão em torno da língua de sinais na educação de surdos.

A efetivação dessa mudança se dá com a promulgação da Lei nº 10.436 de 2002 que reconhece a como meio legal de comunicação e expressão que "[...] constitui um sistema linguístico de transmissão de ideias e fatos, oriundos de comunidades de pessoas surdas do Brasil", embora estabeleça, todavia, que a Libras não substitui a modalidade escrita da Língua Portuguesa (BRASIL, 2002).

Desta forma, mesmo com a mudança de paradigma, o conhecimento da Língua Portuguesa na modalidade escrita não perde sua importância e seu ensino, de acordo com Carneiro, Silva e Nogueira (2017) é motivo de preocupação por parte dos educadores, sejam eles oralistas ou bilinguistas, porque ler e escrever ainda é um enorme desafio para os estudantes surdos.

A interação pela linguagem assegura a humanização das pessoas. A privação de interações linguísticas impõe prejuízos acentuados no processo de

\footnotetext{
${ }^{4} \mathrm{O}$ oralismo é a abordagem educacional que privilegia a oralização dos surdos, mediante o uso de próteses auditivas, do treinamento auditivo, e da aprendizagem da leitura labial. Para o oralismo, a denominação utilizada para as pessoas com dificuldades de audição é de deficiente auditivo. O bilinguismo considera que a primeira língua do surdo é a Língua de Sinais, no caso do Brasil, a Libras e depois, como segunda língua ele aprende a Língua Portuguesa na modalidade escrita. A denominação adotada pelo bilinguismo para a pessoa com limitações auditivas é surdo.
} 
desenvolvimento de todos os sujeitos. Não são apenas os surdos que enfrentam dificuldades dessa ordem. Entretanto, por serem usuários de uma língua sinalizada, eles foram penalizados, ao serem obrigados a empregar uma língua oral, ou a representação escrita dessa língua, ambas de difícil acesso para pessoas privadas da audição (CARNEIRO; SILVA; NOGUEIRA, 2017, p.16).

As autoras reforçam ainda que uma das principais causas de exclusão das pessoas surdas da sociedade se deve ao fato de que, embora em muitos casos sejam consideradas alfabetizadas, elas sejam iletradas, ou seja, não compreendem o que lêem.

Em relação aos surdos, cabe considerar que, quando ocorre o domínio da escrita, esta lhe confere autonomia e poder, visto que a escrita permite e facilita a comunicação com pessoas ouvintes que não conhecem a língua de sinais. Assim, a escrita é uma necessidade, para aproximar a minoria surda usuária de Libras, da maioria ouvinte usuária do Português. Nesse sentido, podemos afirmar que a escrita é uma ferramenta de acessibilidade (CARNEIRO; SILVA; NOGUEIRA, 2017, p.16).

Praticamente de maneira sincrônica à mudança de paradigma educacional, nos anos finais do século XX, e de modo mais intenso a partir deste século XXI, os recursos tecnológicos de informação e comunicação abriram novas possibilidades de comunicação e de acesso à informação para os surdos.

Alguns novos recursos tecnológicos, quando adequadamente empregados, favorecem a acessibilidade dos surdos à comunicação e, assim, permitem sua inclusão social. Em algumas cidades brasileiras, o poder público tem proporcionado o acesso à internet gratuitamente, ampliando o número de usuários. Para os surdos, recursos sofisticados como celulares com tecnologia Ipod IOS ou Android, representam muito mais do que status social. Eles dizem respeito à busca de condições de igualdade na comunicação, enfim representam ferramentas de acessibilidade.

A comunicação com apoio de tecnologias não favorece apenas os contatos a distância. Para os surdos eles são utilizados até mesmo nas interlocuções presenciais com ouvintes não usuários de Libras. Nesses momentos estes recursos são empregados para escrever "bilhetes" digitais. Para Goettert (2014), as novas tecnologias estão acessíveis aos cidadãos surdos, contribuindo não apenas para o fortalecimento e compartilhamento de informações entre eles, mas favorecendo o contato social entre surdos e ouvintes, de maneira que não apenas os conhecimentos, mas também os valores culturais possam ser compartilhados.

Cônsolo (2014), em pesquisa realizada com professores de uma escola especializada para surdos na cidade de São Paulo, destaca a importância dos recursos tecnológicos para a acessibilidade das pessoas surdas na comunicação. Destacamos aqui, fragmento da "fala" de uma das entrevistadas de Cônsolo (2014), que retrata bem os 
resultados encontrados na investigação realizada: “A tecnologia, hoje, para o surdo é fundamental. Toda e qualquer forma de comunicação visual para ele é fundamental, e com a tecnologia isso é possível” (CÔNSOLO, 2014, p.107).

Um dos professores surdos entrevistados por Cônsolo (2014) destaca, ainda, o contato com a Língua Portuguesa escrita como a principal vantagem dos recursos tecnológicos, conforme se pode aferir do fragmento desta entrevista, extraído de Cônsolo (2014, p.108): “A tecnologia é um recurso, hoje, muito útil na vida do surdo. A principal vantagem que os surdos tiram em utilizá-la é o contato com a língua portuguesa e através dela a comunicação escrita".

As relações de trabalho também são favorecidas com os recursos tecnológicos. A "conversa" entre colegas, entre "chefe" e empregado, as orientações das instituições e empresas são compartilhadas, de maneira muito mais ágil com os recursos tecnológicos, isto é, os ouvintes e surdos se relacionam mediante mensagens de celulares, WhatsApp e emails.

As possibilidades de compartilhamento e de trocas midiáticas na rede proporcionam diferentes formas de aprendizado e estimulam o interesse pela busca e pela autonomia do indivíduo. As trocas ampliam o conhecimento de mundo e fortalecem culturalmente as relações entre surdos e ouvintes [...] A tecnologia favorece o surdo no sentido de desenvolver maior autonomia, isto é, além da liberdade de pensar por si e da capacidade de guiar-se por princípios que concordem com a própria razão refere-se à consciência cidadã $[\ldots]$ (GOETTERT, 2014, p.50).

A internet amplia e potencializa o acesso à liberdade e à autonomia. A informação disponibilizada na rede sacia e fomenta a curiosidade, fornece informações e favorece a construção do conhecimento de maneira independente da escola. Com os recursos tecnológicos atualmente disponíveis, o acesso à informação e ao conhecimento passou a ser possível dentro e fora da escola. Entretanto, a escola se apresenta como espaço privilegiado para oportunizar os conhecimentos necessários para que se possa usufruir desses recursos, dentre esses conhecimentos encontra-se a leitura em Língua Portuguesa.

A condição sensorial dos surdos reforça ainda mais a importância dos recursos tecnológicos no seu dia a dia. Um ouvinte tem acesso espontâneo à informação pela via da audição. Assim, o ouvinte pode estar na cozinha da sua casa e ter acesso a uma informação apenas ouvindo um rádio, ou televisão ou ainda, uma conversa de familiares em outro cômodo. Para o surdo, as informações se tornam plenamente acessíveis pela via visual. Assim, a presença física do emissor da informação é fundamental e isto pode ser facilitado com as ferramentas tecnológicas atualmente disponíveis. 
Considerando então, que com os recursos tecnológicos os surdos passaram a utilizar, com maior intensidade, a Língua Portuguesa na modalidade escrita em suas interações sociais, é legítimo indagar se o uso das tecnologias atuais impactariam a aprendizagem da escrita pelo surdo.

Para responder a esta questão, foi necessário estudar três aspectos a saber: a) se os surdos utilizam a Língua Portuguesa escrita para se comunicar virtualmente e qual a importância que atribuem a esta forma de comunicação; b) se a utilização de softwares que apontam erros de grafia e sintaxe poderiam contribuir com a aprendizagem da escrita e c) Se os surdos alfabetizados compreendem o que leem. Cada uma dessas questões se constituiu em uma etapa de investigação realizada com dez surdos, membros de uma Associação de Surdos, educados segundo a abordagem oralista.

A primeira etapa teve por objetivo identificar a importância atribuída pelos surdos à Língua Portuguesa escrita além da familiaridade e o uso pelos surdos dos diferentes instrumentos de comunicação digital. A segunda buscou identificar se havia percepção dos surdos sobre os equívocos cometidos em suas produções escritas e, a terceira procurou identificar a competência desses sujeitos na interpretação de textos (CARNEIRO, 2016).

Resultados parciais dessas três etapas já foram apresentados em diferentes eventos científicos pelas autoras $^{5}$ e são referenciados neste trabalho. Este artigo apresenta uma visão holística da investigação realizada.

\section{Percursos metodológicos}

Selecionamos para a composição do grupo de participantes, sujeitos escolarizados, que haviam sido educados na perspectiva oralista. Dos dez participantes, integrantes de uma associação de surdos e com idades entre 25 e 40 anos, seis possuíam escolaridade em nível superior e quatro em nível médio. Nossa intenção nessa escolha foi identificar o uso social das tecnologias de comunicação ${ }^{6}$, com ou sem o uso da escrita, e os benefícios em linguagem e aprendizagem percebidos pelos usuários. Atribuímos aos colaboradores nomes fictícios.

\footnotetext{
${ }^{5}$ Os resultados referentes à primeira etapa da investigação foram apresentados V SIPEQ e no CIET / ENPED e os da segunda etapa no VIII CBEE, todos em 2018. Os resultados da terceira etapa foram publicados na Revista Imagens da Educação em 2017.

${ }^{6}$ Por "uso social das tecnologias de informação" neste artigo consideramos a utilização de meios digitais de comunicação nas interações sociais.
} 
Apresentamos, a seguir, quadro síntese das características dos sujeitos colaboradores de nossa investigação.

\begin{tabular}{|l|l|l|l|l|l|}
\hline Nome & Idade & Sexo & Grau de surdez & Formação & Modalidade de Comunicação \\
\hline ALICE & 25 & F & SEVERA & Pós-grad. & Língua oral, Português escrito e Libras \\
\hline CRISTINA & 44 & F & PROFUNDA & Ensino M. & Português escrito e Libras \\
\hline DAIANE & 28 & F & PROFUNDA & Pós-grad. & Língua oral, Português escrito e Libras \\
\hline DOUGLAS & 28 & M & PROFUNDA & Graduação & Língua oral, Português escrito e Libras \\
\hline ELOISA & 35 & F & PROFUNDA & Ensino M. & Português escrito e Libras \\
\hline FABIOLA & 26 & F & SEVERA & Pós-grad. & Língua oral, Português escrito e Libras \\
\hline MAURICIO & 37 & M & PROFUNDA & Graduação & Língua oral, Português escrito e Libras \\
\hline RODRIGO & 26 & M & PROFUNDA & Ensino M. & Língua oral, Português escrito e Libras \\
\hline SAMUEL & 28 & M & PROFUNDA & Ensino M. & Português escrito e Libras \\
\hline TATIANE & 37 & F & PROFUNDA & Pós-grad. & Português escrito e Libras \\
\hline
\end{tabular}

Quadro 1: Perfil de sujeitos surdos

Fonte: Carneiro (2016)

O objetivo geral da pesquisa foi investigar se o uso das tecnologias atuais impactariam a aprendizagem da escrita pelo surdo. Para alcançar este objetivo, foram estabelecidos os seguintes objetivos específicos:

i. Identificar se, quais e como os surdos colaboradores da pesquisa utilizam recursos tecnológicos em suas interações cotidianas.

ii. Identificar a importância atribuída pelos sujeitos à Língua Portuguesa escrita em suas interações cotidianas.

iii. Identificar se ferramentas tecnológicas como o software WordOffice podem contribuir para a aprendizagem da língua escrita.

iv. Identificar as competências dos sujeitos na leitura e interpretação de um texto.

Considerando a amplitude da investigação, a opção metodológica adotada foi a realização em três etapas, embora os sujeitos fossem os mesmos.

Para cada etapa os instrumentos de coleta dos dados foram diferentes, no entanto em todas foram realizadas entrevistas com os sujeitos, o que é detalhado na apresentação de cada etapa. As entrevistas foram realizadas sempre em Libras, por uma das pesquisadoras que também é surda, e gravadas em vídeo com o auxílio de um smartphone sendo posteriormente transcritas.

Cada sujeito participou de um encontro individual com a pesquisadora surda, com duração em média de 80 minutos assim distribuídos: 15 minutos para a realização do 
solicitado na primeira etapa, 35 minutos para a segunda e 30 minutos para a terceira. Todos os procedimentos foram videogravados para posterior análise.

Apresentamos a seguir cada etapa, no que se refere à questão norteadora, o instrumento de coleta de dados e a análise e discussão destes dados.

\subsection{Etapa 1 ou A importância da língua portuguesa escrita nas interações cotidianas de adultos surdos mediante recursos tecnológicos ${ }^{7}$}

A primeira etapa de nossa investigação foi norteada pela seguinte questão de pesquisa: É fato que são muitas as possibilidades de recursos tecnológicos para a utilização pelos surdos, mas estariam eles efetivamente usufruindo desses recursos? Se sim, quais são os preferidos por eles? E em quais situações de interação os surdos os utilizam?

O instrumento utilizado para a coleta dos dados nesta etapa foi uma entrevista sustentada em um roteiro com 16 questões abertas, respondidas sem a nossa intervenção, isto é, as respostas não eram discutidas. Entretanto, caso os sujeitos apresentassem dúvidas a respeito das questões elas eram reformuladas até que o colaborador se sentisse em condições de responder. Depois de analisar as respostas de cada sujeito, foram estabelecidos os pontos em comum que permitiram responder à questão norteadora,

As questões não foram entregues aos sujeitos por escrito, mas formuladas por uma das pesquisadoras, diretamente em Libras. Elas buscavam identificar a experiência de cada um deles no uso social das ferramentas tecnológicas: de quais recursos tecnológicos eles dispõem e utilizam; se têm acesso à internet; se consideram o uso da escrita digital difícil; quais são suas preferências, vídeo ou texto, para se comunicar com sujeitos ouvintes e surdos (CARNEIRO, 2016).

O roteiro para a entrevista foi composto das seguintes questões: 1) Você acessa os recursos tecnológicos sempre? Às vezes? Raramente? 2) Em quais situações você usa a leitura e a escrita? 3) Já sentiu dificuldade em usar a escrita? 4) Acessa internet todos os dias, algumas vezes na semana, raramente ou nunca? 5) Qual o site você acessa mais? 6) Utiliza o celular para enviar e receber mensagens sempre? Com quem você se comunica nessas situações? 7) E quanto ao e-mail? Você utiliza esse recurso para se comunicar? Com quem você se comunica nessas situações? 8) Como seria sua vida sem a

\footnotetext{
${ }^{7}$ Esta parte traz elementos que constam de artigo das autoras publicado, nos Anais do VSIPEQ: V Seminário Internacional de Pesquisa e Estudos Qualitativos, realizado em Foz do Iguaçu em 2018.
} 
possibilidade de se comunicar por meio de mensagens no celular e no e-mail? Faria falta para você? O que você sentiria? 9) Você acha que é difícil compreender plenamente as informações escritas, através da Língua Portuguesa, nos meios de comunicação, por exemplo, jornal, revista, televisão com legenda, computador, tablet, livros, enfim, todos os recursos tecnológicos que empregam a escrita? 10) Você assiste televisão com legenda? Se fosse sem legenda, o que você sentiria? 11) Acha que as novas tecnologias são importantes para os surdos? 12) Você prefere os recursos tecnológicos que permitem sinalizar na webcam, por exemplo, "viável"8, "Skype", oovoo e outros; ou prefere escrever e digitar em português escrito, em recursos como o celular, e-mail, facebook, ente outros? 13) Você acha que aprendeu escrever melhor usando as ferramentas tecnológicas do que usando livro impresso e papel? 14) Você passou a usar mais a escrita com o avanço dos recursos tecnológicos, ou a frequência do uso da escrita não se alterou na sua vida? 15) Quando você desconhece uma palavra escrita, em Português, como você procura seu significado? Que recursos utiliza nessas situações? 16) Você acha que o Português escrito é importante em sua vida? Por que?

Em função da limitação do espaço de um artigo, apresentamos uma síntese dos resultados obtidos, possibilitando, sempre que for pertinente, a "palavra" ao colaborador.

Todos os colaboradores de nossa investigação utilizam celulares cotidianamente e, no que se refere aos demais recursos tecnológicos, sete afirmam utilizar sempre, enquanto que dois, apenas às vezes e um dificilmente. A justificativa para a utilização quase que exclusiva do celular (smartphone) é que eles já apresentam recursos como acesso à internet (wifi), redes sociais e diferentes aplicativos, como o whatsApp e IMO, além de estar sempre ligado e disponível.

Apesar de preferirem os aplicativos em vídeo, muitos afirmam que não possuem dificuldades na utilização social do Português ${ }^{9}$ escrito, sendo que um sujeito, inclusive afirma que, depois que passou a conviver apenas com surdos e a se comunicar quase que exclusivamente em Libras, "se esqueceu" um pouco da Língua Portuguesa, atualmente esse sujeito tem vontade de voltar a aprendê-la.

Antes eu entendia melhor e escrevia melhor porque convivia só com ouvintes. Depois comecei a conviver mais com os surdos e a utilizar português e Libras. Agora quase deixei o português de lado e uso só Libras. Sou feliz assim. Mas

\footnotetext{
${ }^{8}$ Foram utilizadas as referências "viável” e Skype, por ser desta forma que os sujeitos colaboradores se referem a esses recursos. A escolha foi feita pela pesquisadora surda participante da mesma comunidade dos sujeitos.

${ }^{9}$ Por "utilização social do Português escrito" estamos considerando interações cotidianas sustentadas nesta forma de comunicação possibilitada pelos recursos tecnológicos como celulares, computadores, dentre outros.
} 
tenho vontade de voltar a escrever. Algumas pessoas diziam que minha escrita era errada. Eu me fechei. Me senti restrita e limitada. De fato, eu escrevo errado. Atualmente estou tentando desenvolver mais minha escrita, retomar minha aprendizagem do início (TATIANE - resposta à pergunta 3).

Outro sujeito reforça essa questão ao afirmar que ele, na maioria das vezes, utiliza os aplicativos de escrita, mas que hoje "[...] com a webcam parece que as pessoas estão usando menos a escrita" (DOUGLAS - resposta à pergunta 12).

No que se refere à leitura, todos afirmam que possuem dificuldades. Se o texto é simples, eles compreendem bem. Como nas interações cotidianas, ou seja, no que se refere ao uso social da escrita, os sujeitos afirmam que não apresentam dificuldades, pois os textos são curtos, simples e contextualizados. Dois sujeitos afirmaram que utilizam a escrita na comunicação com ouvintes e vídeos em Libras, principalmente para a comunicação com surdos não letrados.

As ferramentas tecnológicas são fundamentais para todos os sujeitos entrevistados. Eles relatam que não conseguiriam mais se adaptar a um mundo sem essas ferramentas, destacando que teriam muita dificuldade de comunicação.

Seria muito difícil porque teria que correr para chamar alguém, seria um "vai e vem", que custaria muito. Hoje é mais fácil, pois as tecnologias possibilitam $\mathrm{o}$ acesso às informações de forma rápida e sem muito custo. Se não tivesse a tecnologia, teria que ir pessoalmente. Antigamente, eu andava de bicicleta para comunicar com as pessoas, e hoje não! Está mais fácil devido a tecnologia. DOUGLAS - resposta à pergunta 10).

Se não existe, parece que eu também não existo, fico sem comunicação, sem ninguém com quem me comunicar. Parece que não existe mais ninguém, que eu não tenho um lugar no mundo. Por exemplo, como os surdos poderiam combinar um encontro? Sem email, como vou saber o que está acontecendo? (FABIOLA - resposta à pergunta 8 ).

Os colaboradores da pesquisa ressaltam, constantemente, a importância dos recursos tecnológicos e como sua qualidade de vida melhorou com eles. De acordo com uma entrevistada, depois que as ferramentas tecnológicas apareceram “[...] não tem como as excluir. Uso eles sempre. Elas estão como que coladas em mim. Nunca se separam" (DAIANE - resposta à pergunta 8).

Ao serem indagados sobre a importância da Língua Portuguesa em suas vidas, houve unanimidade acerca da necessidade de o surdo conhecer as duas línguas. $\mathrm{Na}$ modalidade escrita, entendem que o Português é um conhecimento obrigatório para os surdos, no entanto, a modalidade oral deve ser uma escolha dos surdos, bem de acordo com o estabelecido na legislação brasileira para a educação bilíngue dos surdos.

A minha opinião, o Português é importante. Mas para os surdos, a Libras está em primeiro lugar e em segundo lugar o Português. Porque estamos "morando" 
no mundo ouvinte. Se o mundo fosse surdo, é claro que só usaríamos a Língua de Sinais. Por vivermos em um mundo ouvinte, ficamos restritos, limitados... Com a Libras, como primeira língua, e o Português, como segunda língua, fica mais fácil a comunicação. Quando não encontro a palavra correspondente em Libras (no diálogo com o ouvinte que não sabe Libras), eu peço para ele esperar e escrevo. Mostro a escrita para ele para me comunicar até nos entendermos. Entendeu. É bom dominar duas línguas, isso favorece a acessibilidade. Para os surdos, e primeiro lugar deve vir a Libras, depois o Português básico (RODRIGO - reposta à pergunta 16).

Com esta etapa buscamos alcançar os dois primeiros objetivos específicos de nossa investigação. No que se refere ao objetivo específico: Identificar se, quais e como os surdos colaboradores da pesquisa utilizam recursos tecnológicos em suas interações cotidianas, os resultados indicam que os sujeitos surdos colaboradores são experientes no uso de ferramentas tecnológicas e não encontram muita dificuldade de acessibilidade à comunicação mediante tais recursos.

Para a consecução do segundo objetivo específico: Identificar a importância atribuída pelos sujeitos à Língua Portuguesa escrita em suas interações cotidianas, considerando que são muitas as ferramentas tecnológicas disponíveis para a utilização pelo surdo, tanto para se expressar em Libras, como o Viável, os softwares IMO e o Skype, quanto pela linguagem escrita, como as redes sociais representadas pelo Facebook e o twitter, esta etapa apontou que a mais utilizada é o celular, principalmente através do aplicativo whatsapp, porque permite a comunicação tanto utilizando a escrita quanto a Libras.

Os entrevistados, não importando sua idade, consideraram que conhecer a Língua Portuguesa na modalidade escrita é fundamental para os surdos. Entretanto, quando se trata de comunicação entre eles, sempre que as condições são possíveis - isto é, "exista um local certo e com apoio" (Maurício)- esta se efetiva, mediante vídeos em Libras. As condições apontadas para a comunicação em vídeo ser efetivada indicam a necessidade de se ter relativa privacidade, contar com aparador para o celular que possibilite ficar com as mãos livres para sinalizarem. Caso contrário, recorrem à escrita, mas essa forma de comunicação apresenta limitações, pois ainda são muitos os surdos não alfabetizados.

Quando a comunicação é entre surdos e ouvintes, a preponderância é pela utilização da escrita pois, neste caso, praticamente todos os ouvintes são "iletrados" em Libras. Esta iteração também apresenta restrições, pois a escrita dos surdos nem sempre é compreendida pelos ouvintes, ficando a comunicação limitada a frases curtas e contextualizadas. É fato que é desta forma que também ocorre a comunicação escrita via 
whatsapp entre ouvintes. A diferença aqui é que quando há necessidade de uma interação mais complexa, os ouvintes recorrem à mensagem audiogravada.

Assim, as possibilidades de comunicação entre ouvintes e surdos, apesar de ter tido um ganho significativo com os recursos tecnológicos, ainda segue restrita em função quer da insuficiência do repertório lexical ou sintático dos surdos, quer do desconhecimento da Libras pelos ouvintes.

Após a constatação da familiaridade e acesso a recursos tecnológicos de nossos sujeitos apesar da fragilidade de sua leitura e escrita conforme seus relatos, nossa investigação avançou no sentido de buscar identificar se ferramentas tecnológicas como o software Word podem contribuir para a aprendizagem da língua escrita, estando estabelecida a segunda etapa de nossa investigação.

\subsection{Etapa 2 ou A percepção dos surdos acerca dos equívocos cometidos em suas produções escritas ${ }^{10}$}

A segunda etapa teve como questão norteadora: Poderiam ferramentas tecnológicas como o software Word contribuir para a aprendizagem da língua escrita pelo surdo ao lhe possibilitar identificar seus equívocos e sugerir alternativas para a sua correção?

A conjectura inicial foi de que como esses softwares corrigem o que está escrito errado, seja na ortografia ou na gramática, poderiam funcionar como um "professor virtual". Além disso, caso as alternativas para as correções apresentadas pelo Word contenham palavras desconhecidas pelo surdo, é sempre possível buscar seu sinônimo, utilizando os mesmos recursos tecnológicos, de maneira a ampliar o vocabulário.

Para responder a esta questão, os sujeitos foram solicitados a produzir um texto manuscrito com aproximadamente 20 linhas, com tema livre, podendo narrar alguma experiência de sua vida pessoal ou profissional, algum episódio escolar, enfim, o que desejassem. Em seguida foi-lhes solicitado que digitassem o texto produzido utilizando o Word. Com os avisos para a autocorreção do software, efetivados por sublinhamento em vermelho ou verde. Todos os sujeitos sabiam o significado do sublinhado em vermelho enquanto que apenas quatro não conheciam o do sublinhado em verde. Após esta tarefa, cada um dos sujeitos foi entrevistado individualmente pela pesquisadora surda apoiada

\footnotetext{
${ }^{10}$ As discussões e análises contém elementos de trabalho apresentado no VIII Congresso Brasileiro de Educação Especial, 2018.
} 
em quatro questões ${ }^{11}$. A análise dessas entrevistas mostrou que os sujeitos perceberam os erros que tinham cometido na escrita no papel.

Todos perceberam seus erros, quando transcreveram seus manuscritos no computador em função dos sublinhados e afirmaram se sentir "confortáveis" ou "com confiança" porque o computador os alertara sobre seus erros e os podiam corrigir. Houve até uma justificativa de que o fato de o computador permitir esta autocorreção imediata é “importante para o meio ambiente”, pois não seria preciso "jogar os papéis". Destacaram ser importante este software porque permite ao escrevente apagar, escrever, corrigir, reescrever, tudo no computador.

Nove dos dez entrevistados mudariam seus manuscritos após a digitação no Word, conforme ilustram os fragmentos a seguir:

\footnotetext{
Eu sinto que o computador me ajuda e eu percebo o que é necessário mudar para colocar certo no papel (SAMUEL - resposta à pergunta 2)

Sim. Porque é diferente. Quando escrevi depois escrevi no computador papel, não prestei muita atenção. Depois, quando digitei no computador, levei um susto, porque vi que tinha muitos erros. Ele me avisa o que mudar (TATIANE - resposta à pergunta 2).
}

No que se refere à experiência de digitar, um declarou que não costuma fazer isto porque "não gosta de computador". Outro disse que preferia escrever no papel, pois o papel não aponta os seus erros. O computador expõe suas limitações e o deixa desconfortável:

Eu prefiro escrever cartas [...] eu digito e aparece errado. Ele (o computador) me avisa os erros. Eu me sinto limitada. Tenho vergonha. Escrevendo no papel, me sinto normal, sem saber de meus erros (inocente) (TATIANE - resposta à pergunta 3).

Os demais, à exceção do sujeito que não usa o computador, ao contrário da citação anterior, consideraram esta percepção positiva:

Eu acho fácil escrever no computador porque ele me avisa. Por exemplo, os sublinhados. No papel fico confuso e não sei como escrever, porque ele [o papel] não avisa se está errado. [No computador] eu vejo o sublinhado e vou arrumar, se está faltando vírgula, ou se a palavra está errada (MAURICIO resposta à pergunta 3).

Outro sujeito, alertou para o risco de se parar de prestar atenção ao que se escreve, deixando esta tarefa exclusivamente para o computador:

\footnotetext{
${ }^{11} 1$ - O que os sublinhados significam?

2- Você mudaria seu texto inicial agora que usou o computador? Por quê?

3-O que você sentiu em escrever no mundo digital?

4-Qual é o melhor para você escrever em papel ou computador?
} 
Na verdade, para mim é melhor a escrita digital, fica mais fácil para escrever. Mas tem um problema, porque você se acostuma com as correções [...] daí quando vai escrever no papel, erra. [...] o computador ajuda a escrever certo [...] mas mostra que não aprendi de verdade [...] Mas você pode pedir ajuda para ele [o computador] e pensar e tomar cuidado e controlar sua escrita pessoal [manuscrito] (DOUGLAS - resposta à pergunta 3)

As informações desta segunda etapa, aliadas às obtidas na primeira, apontam quase que para um paradoxo, pois os surdos entendem que o Português é importante para eles se incluírem no mundo ouvinte, têm consciência de suas limitações na escrita e reconhecem que o computador os auxilia a escrever melhor, mas, quando se trata de estabelecer qual forma de escrita tem sua preferência, não existe preponderância da escrita digital sobre a manuscrita, pois apenas quatro dentre os dez entrevistados responderam preferir a escrita digital. Isto indica que, para uma parte expressiva dos sujeitos desta investigação, os equívocos cometidos não incomodam, ou seja, que escrever errado é algo que já se naturalizou para eles. Escrever corretamente não se traduziu em sua preocupação maior, uma vez que dos quatro sujeitos que preferem utilizar a escrita digital, somente um deles apontou preferir o computador porque com ele poderia escrever mais corretamente.

O melhor é computador. [...] ele me ajuda se escrever (à mão) não dá para entender [...] o computador sim é melhor. Eu prefiro (ELOISA - resposta à pergunta 4).

Um sujeito não justificou sua escolha e para dois outros sujeitos, a razão para preferir a digitação não está relacionada a "escrever correto" e sim à praticidade e ao fato de não "gastar muito papel”.

Digitar, parece que me ajuda mais desenvolver, mais ideias, por exemplo, escrever no computador, as palavras ficam na página, eu arrumo, mudo, dá menos trabalho, também conserto. Escrever no papel, mais papel, escrever repetindo. [...] (DAIANE - resposta à pergunta 4).

[...] Digitar é mais gostoso, no computador pode apagar, gasta menos papel e caneta, o computador pode apagar, parece gastar menos papel e caneta [...] (MAURICIO - resposta à pergunta 4).

Dois sujeitos declararam preferir exclusivamente escrever no papel:

O melhor é escrever no papel, porque é bom escrever, é diferente, é minha mão. O computador é ruim e diferente, palavra difícil que já senti, parece que não é minha mão que escreveu. (CRISTINA - resposta à pergunta 4).

Para mim escrever no papel é melhor, gosto mais (TATIANE - resposta à pergunta 4$)$.

Outro estabeleceu sua preferência pelo papel, mas se fosse necessário, utilizaria o computador, dependendo da situação. 
$\mathrm{Na}$ verdade gosto escrever no papel, porque é mais fácil para mim escrever e não tenho paciência no computador porque digito com dificuldade [...] se a pessoa não conseguir ler minha escrita por causa das letras e feias, eu uso o computador e imprimo. Depende da situação (DOUGLAS - resposta à pergunta 4).

Outros três sujeitos declararam que digitar ou escrever à mão é indiferente. $\mathrm{E}$ destacaram que as duas formas são importantes.

Para mim, melhor os dois, porque o papel é durável, quem sabe computador quebra e fico desesperada [...] também papel pode pegar fogo, então melhor usar os dois. Escrever ou digitar os dois. Eu uso os dois (FABÍOLA - resposta à pergunta 4).

A resposta é complicada, os dois são importantes. [...] precisa um pouco as mãos escreverem no papel, parece como exercício físico, músculos das mãos. Se só escrever no teclado terá dores de mãos, problemas, não quero, melhor pouco computador pouco papel eu gosto os dois (RODRIGO - resposta à pergunta 4).

Para identificar se a utilização da escrita pelos sujeitos corresponde ao que pensam, após essa entrevista, foi solicitado que eles narrassem, agora utilizando a Libras (o que foi gravado e posteriormente transcrito), o manuscrito produzido. Seis dos sujeitos somente traduziram para Libras seu manuscrito, apoiando-se na leitura e sinalizando simultaneamente em Libras, não na forma de Português sinalizado. Outros fizeram seu relato de memória e pouco alteraram o texto.

Pudemos perceber que nesta última atividade, os sujeitos ficaram empolgados e a narrativa demonstrou ser mais complexa, completa e profunda do que o texto escrito produzido. Um sujeito, Cristina, todavia, chamou a atenção. Exatamente o que possui o menor grau de escolaridade e que apresentou maiores dificuldades em todas as etapas anteriores da entrevista, particularmente em compreender o que lhe era indagado, fez o relato sinalizado "de memória" e o que havia escrito em apenas quatro linhas e que ao ser digitado ficou reduzido a duas em função de sua dificuldade com o Português, foi transcrito e digitado em 13 linhas.

Para ilustrar este fato, trazemos na Figura 1 o que Cristina escreveu e como narrou sua vida em Libras, primeiro, o que ela escreveu: 


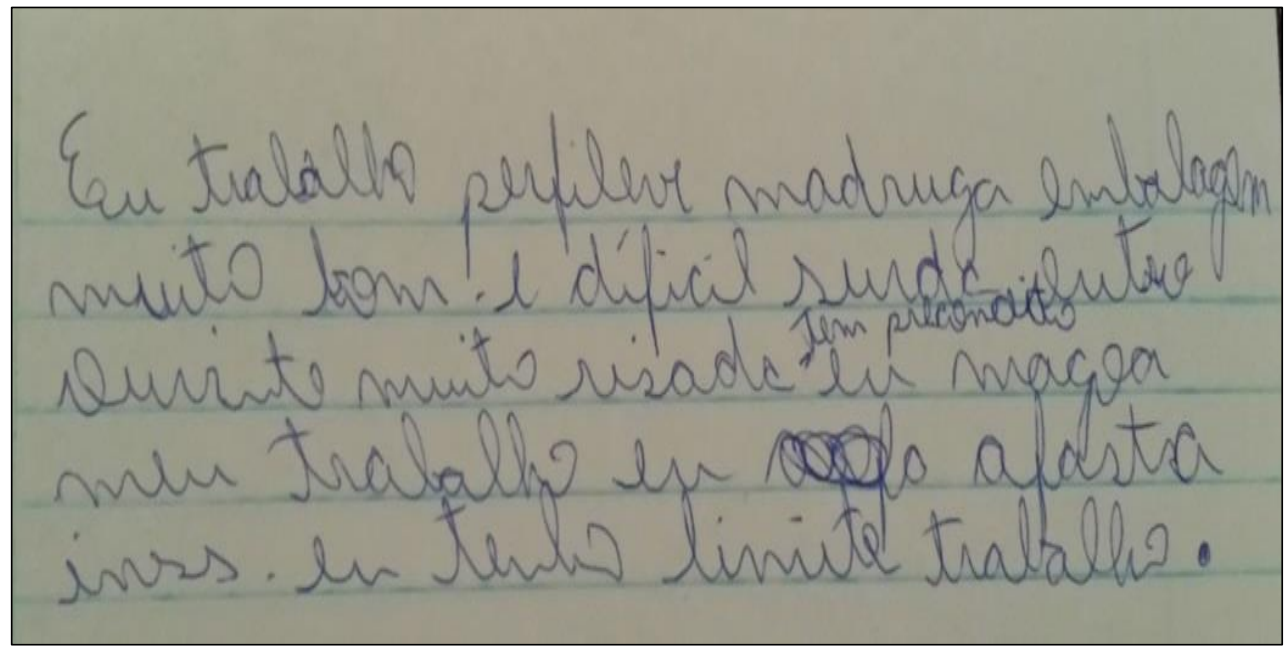

Figura 1: Texto produzido por Cristina

Fonte: Carneiro (2016)

A seguir, apresentamos a transcrição do que Cristina narrou em Libras: $E u$ trabalho na madrugada, trabalhar com o silencio é bom e tranquilo. Finjo não ter surdos ao meu redor no trabalho. Eu e um ouvinte conversamos, os outros ouvintes me olham, riem por causa dos gestos e provocam. Eu vejo e me amarguro no coração, fico magoada. Acho que estou no limite e estando magoada, fico quieta. Um dia, aconteceu um problema no meu ombro e recebi INSS, fiquei afastada. Sinto que tenho limites no meu trabalho, sei lá. No passado, trabalhei na Recco, hoje sou diarista e trabalho na Perfileve, O INSS venceu, sinto dor no meu ombro, o médico do trabalhador me liberou a voltar ao trabalho. Estou voltando e a dor no ombro continua, tenho medo de reaparecer o problema. Nossa, dói muito e sinto barulho no ombro. Falei para alguém do trabalho: “desculpe, meu ombro está aumentando a dor de novo, estou tomando remédio e parei de trabalhar há 5 meses e estou recebendo INSS. Só!

O desempenho de Cristina demonstra que seu pensamento fluiu muito mais em Libras, ficando limitado pela escrita. Isto demonstra que quando se pensa e se expressa em Libras, o sujeito é fluente e profundo. Quando pensa para escrever em Português, ele fica mais limitado. $\mathrm{O}$ caso de Cristina foi o que mais se destacou, entretanto, todos os demais colaboradores que não leram seus respectivos textos, aprimoraram seus relatos, inserindo novas observações.

As análises dos resultados dessas duas etapas apontaram que os entrevistados tinham acesso e familiaridade no uso de recursos tecnológicos; consideravam o conhecimento da Língua Portuguesa escrita importante, reconheceram que softwares podem auxiliar na correção dos equívocos cometidos, porém, dois aspectos não previamente considerados ficaram evidentes: ao contrário do que nossa conjectura inicial 
previa, emergiu a consideração de que o uso das ferramentas tecnológicas os afastavam da língua escrita, mencionado por dois dos entrevistados e a naturalização em relação aos equívocos apresentados em suas produções escritas.

Para a consecução de todos os objetivos específicos e finalmente responder à nossa questão central de pesquisa, restava identificar a competência dos sujeitos em relação à leitura e interpretação de textos, uma vez que a leitura é componente indissociável da escrita. Esse foi o objetivo da terceira etapa.

\subsection{Etapa 3 ou $O$ uso social da Língua Portuguesa escrita pelo surdo: competência na interpretação de uma notícia ${ }^{12}$}

Para a terceira e última etapa de nossa investigação tivemos como pressuposto que, conforme estabelecido no parágrafo único do Artigo $4^{\circ}$ da Lei $10.436 / 2002$, a Lei da Libras (Brasil, 2002), destacado anteriormente, a aprendizagem da escrita não é considerada opcional na educação de surdos. Mas estaria essa aprendizagem acontecendo de forma efetiva? Assim, a questão norteadora desta etapa foi: Os surdos que avançaram em sua escolaridade e, portanto, são alfabetizados, teriam competência para interpretar um texto em todos os seus detalhes e de serem fiéis ao que estão lendo, isto é, sem realizar inferências a respeito?

Esta pergunta é pertinente porque, na maioria das vezes, em situações de ensino com a presença do intérprete, o surdo quase não lê, pois os conteúdos são sempre interpretados e, portanto, não existe diferença se ele sabe ou não ler com significado. $\mathrm{O}$ surdo pode ser alfabetizado, isto é, consegue ler o que está escrito, mas nem sempre compreende.

Para a coleta de dados o instrumento foi uma notícia de um site na internet e o objetivo foi identificar a interpretação deste texto pelos sujeitos. Para isso foi solicitado aos participantes que o lessem e o explicassem em Libras. O que procurávamos era saber se a informação apresentada pelo texto fora compreendida pelo sujeito surdo.

A notícia relata um acidente de carro. Apesar de estar disponibilizada on-line, imprimimos a matéria e entregamos para os sujeitos da pesquisa, o que se revelou apropriado, uma vez que a maioria deles precisou ler mais de uma vez para compreender. A seguir, o fragmento da notícia que foi instrumento para a coleta de dados desta etapa.

\footnotetext{
${ }^{12}$ Para a apresentação dos resultados desta etapa, recorremos a excertos retextualizados de publicação das na Revista Imagens da Educação, que consta das referências.
} 
Três pessoas morreram em um acidente entre um carro e uma caminhonete na manhã desta sexta-feira (29). Segundo a Polícia Rodoviária Federal (PRF), a batida de frente foi no km-442, da BR-369, em Ubiratã no oeste do Paraná. De acordo com a PRF, o motorista da caminhonete, que seguia no sentido Campo Mourão, no centro-oeste do estado, invadiu a pista contrária e bateu contra o carro. Ele fez o exame do bafômetro, que não apontou a ingestão de álcool. Dois homens, de 35 e 48 anos de idade, e uma mulher, de 36 anos, que estavam no carro morreram no local. Os corpos foram levados para o Instituto MédicoLegal (IML) de Campo Mourão. O condutor da caminhonete, de 24 anos, teve ferimentos leves e foi encaminhado para um hospital em Ubiratã. Segundo a PRF, ele vai responder por triplo homicídio ${ }^{13}$.

Todos os sujeitos leram o texto noticiando o acidente no site e, então explicaram em Libras o que haviam compreendido. Depois de uma primeira tentativa de leitura no site, todos passaram a se valer da notícia impressa. Foi possível constatar que, de maneira geral, todos compreenderam a notícia. Entretanto, alguns detalhes ou foram omitidos ou criados por alguns sujeitos.

Apenas quatro sujeitos leram a notícia e a interpretaram sem fazer a tradução literal, isto é, ler e passar para Libras "palavra por palavra". Pudemos identificar que quatro sujeitos (Alice, Daiane, Samuel e Fabíola) apresentaram uma boa compreensão da notícia, embora não tenham especificado alguns detalhes e criado outros que não constavam do texto.

Alice demonstrou ter compreendido bem a notícia mas omitiu a parte referente ao motorista que provocou o acidente ser indiciado pelo triplo homicídio. Será que ela não compreendeu ou entendeu que esta informação não era relevante?

\begin{abstract}
$\mathrm{O}$ assunto é acidente, três pessoas [cara triste]. A notícia falou que três pessoas no veículo, só um homem de outra caminhonete. Os dois veículos em movimento, quando a caminhonete passou para pista contraria e bateu com o outro veículo. Neste veículo, três pessoas morreram na hora, no local do acidente. Dois homens, um com 35 e o outro com 48 anos, e uma mulher de 36 anos, todos morreram. Um homem se feriu levemente e foi para um hospital em Ubiratã [soletrou]. [Pausou e releu o texto]. Os policiais desconfiaram, então ele entregou o bafômetro para ver se o motorista estava bêbado e teria, assim, causado o acidente. $\mathrm{O}$ homem não havia bebido nenhuma bebida alcoólica. Com [não sinalizou ferimentos] leves foi para o hospital (Alice).
\end{abstract}

13 Disponível em: <http://g1.globo.com/pr/oeste-sudoeste/noticia/2015/05/tres-pessoas-morrem-emacidente-entre-carro-e-caminhonete-na-br-369.html>. Acesso em: 03 jun. 2015 
Daiane, por sua vez, além de não mencionar o encaminhamento dos corpos ao IML acrescenta informações que não aparecem na notícia e que resultam de suas reflexões.

Assunto é uma notícia de jornal, relatando o que aconteceu no dia 29, sexta feira de manhã. O que aconteceu? Aconteceu que na estrada BR 369, região de Ubiratã do Paraná teve um acidente de caminhonete. Um motorista de 24 anos, sozinho, correu dirigindo normalmente, ele foi precipitado na ultrapassagem. No outro carro, 3 pessoas, 2 homens de 35 e 48 anos de idade, uma mulher, 36 . Os dois veículos bateram de frente, no carro com 3 pessoas. Todas morreram na hora. O homem da caminhonete, jovem, 24 anos, não morreu. $\mathrm{O}$ grupo de polícia investigou o bafômetro e não encontrou nada de álcool. Mas motorista da caminhonete vai para justiça devido à morte das 3 pessoas (Daiane).

Percebe-se a presença de inferências como afirmar que o motorista estava dirigindo normalmente mas que foi precipitado. Como ela pode fazer tais afirmações, uma vez que a notícia apenas informa que o motorista invadiu a pista contrária.

Samuel não só omite a questão do bafômetro como faz inferências ao afirmar que o motorista ultrapassou na faixa amarela proibida, informação que não consta na notícia; não menciona que o motorista será indiciado pelo triplo homicídio. Simplesmente desconsiderou esta informação ao encerrar sua explicação sinalizando "só".

O jornal mostra um acidente de veículos que aconteceu em Ubiratã entre um carro e uma caminhonete. Tinha 3 pessoas num carro. Tinha um homem numa caminhonete. As três pessoas eram, 2 homens, com 35 anos e o outro com 48 , e uma mulher de 36 anos. Na caminhonete, outro homem jovem, com 24 anos. $\mathrm{O}$ homem na caminhonete estava viajando na avenida. Ele ultrapassou na faixa amarela proibida. Contudo, ele bateu contra o outro carro com 3 pessoas que morreram na hora. $\mathrm{O}$ homem da caminhonete não morreu, sobreviveu e só teve machucados leves. As 3 pessoas mortas foram levadas para o IML em Campo Mourão. E o homem sobreviveu e foi para um hospital de Ubiratã. Só (Samuel).

Fabíola demonstrou ter a mais completa compreensão da notícia lida, talvez por recorrer ao texto impresso da notícia durante toda sua explicação. Ela não deixou nenhum detalhe sem ser mencionado, inclusive repetindo alguns.

Agora, o jornal divulgou sobre acidente de carro, 3 pessoas mortas por causa de um acidente. Um carro e uma caminhonete, sexta feira de manhã. A Polícia foi ver o acidente que fica na BR 368, ops, é 369. Certo 369! Lá em cidade de Ubiratã, a caminhonete estava indo para Campo Mourão, sabe como é a pista (mão dupla: uma ida e uma volta). O homem da caminhonete ultrapassou na outra pista [contraria]. Não pode ultrapassar, mas ele ultrapassou. $\mathrm{O}$ carro e a caminhonete bateram de frente. $\mathrm{O}$ homem de caminhonete foi fazer o exame para verificar se estava alcoolizado, mas nada [não estava]. No carro, dois homens de 35 e 48 anos de idade, e uma mulher 36 anos de idade, morreram. E o outro homem da caminhonete, com 24 anos, ficou levemente ferido, mas está no hospital em Ubiratã. [lendo e narrando] Os 3 morreram na hora e foram levados para o IML em Campo Mourão. E de novo, o homem da caminhonete, com 24 anos, com ferimentos leves [repetido], foi levado para um hospital em Ubiratã, ele vai responder pelo motivo do acidente que matou 3 pessoas no carro (Fabiola). 
Os demais sujeitos (seis) que optaram pela tradução palavra por palavra, omitiram detalhes ou fizeram inferências, sendo que um sujeito teve muitas dificuldades, pois necessitou de esclarecimentos constantes da pesquisadora para compreender o significado de palavras como "triplo", "pista”, “apontou”.

Estes resultados corroboram com os estudos de Fernandes (2006), para quem os surdos, em suas tentativas de leitura, procuram justapor as estruturas da Libras e da Língua Portuguesa, dificultando a compreensão do texto escrito.

\begin{abstract}
Ao se depararem com o texto escrito, o primeiro impulso é ir sinalizando linearmente palavra por palavra (pulando as desconhecidas), o que é uma estratégia inadequada que não garante a compreensão dos enunciados. Primeiro por não haver isonomia estrutural (correspondência termo-a-termo) entre o português e a língua de sinais. Segundo, porque sinalizavam o primeiro significado que lhes vinham à cabeça, não necessariamente o sentido atribuído à palavra no contexto (FERNANDES, 2006, p.11).
\end{abstract}

Cristina apresentou muitas dificuldades. Conseguiu entender que houve um acidente de carro e que morreram pessoas. Confundiu a palavra Rodoviária da expressão Polícia Rodoviária, com Estação Rodoviária. Entendeu Instituto Médico Legal - IML como sendo um médico "legal”. Sem os esclarecimentos que solicitou à pesquisadora surda não conseguiria sequer uma noção geral da notícia:

\begin{abstract}
$\mathrm{O}$ assunto é uma notícia de jornal que relata um acidente. Três pessoas morreram no carro que bateu em um caminhão. De manhã, dia 29 sexta feira, segunda hora policial, Policia Rodoviária [sinalizado como estação rodoviária] Federal, o local da batida foi no endereço PR 432 BR 369 - Ubiratã [soletrou] no oeste do Paraná. O acordo [sinal de confirmação] ou acordo [sinal de despertar], sei lá. É acordo [soletração] de PRF, o motorista de caminhão foi no sentido para Campo Mourão, no Centro Oeste do Estado. Não sei o que é pista? Desculpe, o que é pista? Não sei [A pesquisadora sinalizou pista]. Ah, pista é o chão de estrada. $\mathrm{O}$ acidente de carro foi encontrado, o homem fez exame de bafômetro? É para expirar o ar no aparelho de bafo? [pesquisadora sinalizou "sim"]. Esqueci, desculpe. Que é A-P-O-N-T-O-U [soletrou] de ingestão [soletrou] de álcool. Dois homens de 35 e 48 anos de idade, uma mulher de 36 anos, estavam mortos no carro. Os corpos foram levados para o lugar de IML - Médico legal [demonstrando emoção] em Campo Mourão. O condutor [soletrou e não sabe o que é] homem de caminhão foi para hospital em Ubiratã [soletrou]. Segundo [soletrou] PRF vai responder sobre triplo [perguntou o que é triplo. A pesquisadora esclareceu 3]. Ah sinal é 3, 3 homicídios. São mortos. Só (Cristina).
\end{abstract}

Dos cinco outros sujeitos, um teve uma boa compreensão da notícia, embora simplesmente soletrasse algumas palavras como IML de Campo Mourão. Não há como afirmar se ele compreende o significado desta sigla:

O assunto do jornal é um acidente. 3 pessoas foram mortas por causa de um acidente de carro, com uma caminhonete. Aconteceu de manhã, dia 29 sexta feira. A Policia Rodoviária Federal investigou e encontrou o caso no local, no KM 442 BR 369 em região de Ubiratã [fez sinal e soletrou], é do Paraná, fica no Oeste. O Motorista da caminhonete estava a caminho de Campo Mourão, e ultrapassou. Outro carro que estava vindo e aconteceu a batida [contra 
caminhonete]. Então aconteceu, a polícia quis fazer o bafômetro no homem que fez a ultrapassagem para verificar se ele tinha álcool ou não. Não tinha nada de álcool mesmo. Fez ultrapassagem e bateu no outro carro. No carro, dois homens de 35 e 48 anos, também uma mulher de 36 anos foram mortos. Os corpos foram encaminhados para o IML em Campo Mourão [sinalizou e soletrou]. E o motorista da caminhonete, 24 anos, teve o corpo machucado levemente e foi encaminhado para Ubiratã [sinalizou e soletrou], quando ele estiver estável, a polícia vai divulgar sobre o motorista da caminhonete que cometeu homicídio. Terminei o assunto do jornal (Rodrigo).

Houve perguntas sobre o significado de palavras como "bafômetro" e "homicídio", que são palavras bastante comuns em jornais. A palavra "apontou" também não foi compreendida por alguns sujeitos, entretanto, após esclarecimentos por parte da pesquisadora, conseguiram avançar, como Douglas, que não sabia o que era "homicídio". Mas, posteriormente à explicação, inferiu que a polícia já havia investigado o que havia acontecido e que posteriormente iria divulgar pela internet:

Então, o jornal espalhou o acontecimento. 3 pessoas bateram, ops, desculpe.
Espere. [Lendo novamente]. Foi pouco tempo atrás, sexta feira de 29 , três
pessoas morreram por causa de um acidente. Um carro e uma caminhonete. A
Policia Federal investigou o que havia acontecido lá na mesma rua, local é KM
422 , o caminho é perto de Ubiratã no Oeste do Paraná. Então, a polícia
investigou sobre acontecimento, a caminhonete no caminho bateu em outro
carro, dois veículos envolvidos. A polícia investigou ele que fez bafômetro,
nada de álcool. Outros homens acidentados no carro ficaram, mortos. Tinham
38 e 48 anos de idade, não é, é 35 , e uma mulher de 36 anos de idade ficaram
mortos no carro. Os corpos foram levados para Campo Mourão e os mortos
deixados no IML. O motorista da caminhonete ficou ferido e doente, e foi
levado para um hospital em Ubiratã. A polícia investigou o que havia causado
o acidente, levando à morte de 3 pessoas. Depois ela vai divulgar pela internet
(Douglas).

Palavras polissêmicas em Português também se configuraram como problema na interpretação da notícia pelos surdos, pois para a expressão "segundo a polícia", três dos colaboradores interpretaram a palavra segundo como número ordinal, o que comprometeu a interpretação. Outra palavra que gerou dúvidas foi "acordo" (de acordo) que um dos sujeitos não sabia se se tratava de "confirmação" (de acordo) ou de "despertar" (acordar pela manhã).

Eloísa fez uma primeira leitura e perguntou as palavras que não conhecia, como apontou e homicídio. Nada perguntou sobre a palavra segundo, que interpretou como número ordinal e mesmo tenho o texto ficado sem sentido ao interpretar "Segundo a Polícia ..." como $2^{\circ}$ a Polícia, isto não a intriga. Além disso, mesmo interpretando palavra por palavra, omite trechos importantes, como, por exemplo, que os corpos foram levados para o IML de Campo Mourão e também parece não compreender que "corpos" se referem a cadáveres, pois afirma que o "corpo do motorista" da caminhonete e não o motorista da caminhonete foi levado ao hospital de Ubiratã: 
Assunto é notícia de jornal sobre acidente. 3 pessoas morreram de acidente de veículos batidos de frente. Era um carro e uma caminhonete. Sexta-feira, dia 29, o segundo [número ordinal $2^{\circ}$ ] de Policia Federal foi no local de trânsito, KM 440, é o local de trânsito em cidade de Ubiratã [soletrou], no Oeste [soletrou] do Paraná. O Motorista da caminhonete foi para Campo Mourão que bateu contra o carro, fez exame de bafômetro e não foi encontrado nada de álcool. 2 homens, um com 35 e o outro com 48 anos de idade e, uma mulher com 36, morreram, no carro, no mesmo lugar do acidente. O motorista da caminhonete, 24 anos, ficou ferido, seu corpo foi para hospital de Ubiratã [soletrou]. Ele responderá pelo motivo do acidente que levou ao que aconteceu: 3 pessoas mortas dentro do carro (Eloisa).

Apesar da tradução "palavra por palavra" da Língua Portuguesa para a Libras ter sido incorreta devido à polissemia das palavras "rodoviária", "acordo" os sujeitos aparentaram ter compreendido o fato geral expresso no texto:

O assunto do Jornal é um acidente de veículo. Vou explicar a história. Três pessoas sofreram acidente de veículo. Um carro aqui e um caminhão simples pequeno em outro lugar. Foi de manhã, sexta feira passada. A Polícia, PRF [sinalizado como Polícia da Rodoviária] foi ao local. O acidente foi no KM 442, não sei onde fica. É em Ubiratã, a cidade, região.... O motorista de caminhão, um homem, ia rumo a Campo Mourão. O outro veículo, era um carro. Os dois bateram de frente. Um homem veio ver exame de bafômetro, e não constatou nada de álcool, nada mesmo, nem pinga. Dois homens, de 35 e 48 anos de idade, morreram e também uma mulher de 36 anos de idade, todos morreram no carro. Os quatro corpos... não! Os três corpos foram levados para IML em Campo Mourão. O homem do caminhão pequeno, foi levado para Ubiratã, ele teve ferimentos leves, simples e ficou no hospital (de Ubiratã). Simples é só isso (Tatiane).

Maurício também confunde "segundo", no sentido de "de acordo com"; com 20; confunde ingestão com intestino delgado; faz inferências sobre como o acidente aconteceu e de que a polícia divulgará os resultados da investigação. Entretanto, faz questão de estabelecer o significado de Polícia Rodoviária Federal, explicando que não se trata da "estação Rodoviária". Entende que "corpos" se refere aos mortos e é o único que sinaliza "homicídios":

O assunto é o Jornal que divulgou: 3 pessoas mortas por causa de um acidente de carro. Um carro e uma caminhonete, sexta feira de manhã, dia 29. Segundo [pensou era segunda feira, mas corrigiu para número ordinal] policia PRF [narrou que o significado da sigla é Policia Federal]. O acidente foi entre dois veículos, com colisão frontal, no KM 442 BR 369, em Ubiratã, no Oeste do Paraná. De acordo com a Polícia, o motorista da caminhonete estava indo no sentido para Campo Mourão, no Oeste do Estado. Ele precipitou na estrada e ultrapassou na outra pista, errou e aconteceu o acidente com o outro carro que estava vindo. Aconteceu, os dois bateram de frente, mas a Polícia já fez o teste do bafômetro para ver se tem álcool, mas não tem nada, o intestino delgado [para Ingestão] nada álcool. Dois homens, com idade de 35 e outro 48 anos, e uma mulher de 36 anos, estavam no carro, mortos e foram levados para o IML de Campo Mourão. No outro veículo, a caminhonete, um homem com 24 anos de idade, teve ferimentos simples. Ele foi levado para o hospital de Ubiratã. Segundo [sinal de número ordinal] Policia Federal vai investigar sobre 3 homicídios e depois divulgará (Mauricio). 
O conhecimento da Libras demonstrado por alguns sujeitos também se mostrou insuficiente pois recorreram à soletração, em muitos casos, indicando desconhecimento de vários sinais. Sete dos sujeitos não identificaram as preposições, por exemplo, "no carro" em Português escrito, e que deveria ser interpretado por "dentro carro" em Libras, foi sinalizada apenas por "carro", o que não retrata a realidade da notícia pois, "estar dentro" é diferente de "estar fora" do carro.

Nenhum sujeito sinalizou a palavra "invadir" e, estranhamente, nenhum deles perguntou o significado desta palavra, demonstrando como eles estão habituados a contextualizar o que leem. Ou seja, a compreensão da notícia é influenciada pelas inferências pessoais. Ao se defrontar com lacunas em sua interpretação, algumas vezes decorrentes da incompreensão dos significados das palavras, a imaginação dos sujeitos procura "explicar" o ocorrido, complementando essas lacunas. Neste caso específico, a a criação de detalhes ou explicações não causou grandes prejuízos para a compreensão do texto, embora uma "invasão da pista contrária" possa ocorrer em diferentes circunstâncias que não a de uma ultrapassagem "precipitada" ou em "local proibido". Mesmo quando não há lacunas, como quando entenderam segundo como $2^{\circ}$, parece que os sujeitos "criam" a lacuna, ou seja, não consideram a palavra em questão ao buscar estabelecer sentido para o que leem.

Os resultados desta terceira etapa confirma as considerações de Silva (2008), para quem o aprendizado do Português escrito é ainda um enorme desafio no campo da educação de alunos surdos usuários ou não de Libras. Mas, a dificuldade é ainda maior na interpretação de textos, o que se caracteriza como um problema, pois sem uma boa capacidade de interpretar textos escritos em Português, é muito difícil para o surdo avançar academicamente.

\section{O que nos dizem os resultados?}

Os resultados que encontramos e que confirmaram nossas hipóteses prévias, advindas de estudos teóricos sobre pesquisas com temáticas similares foram:

a) Os surdos entrevistados possuem acesso e familiaridade no uso de diferentes recursos tecnológicos que favorecem suas iterações cotidianas. O acesso é garantido pela facilidade com que os celulares estão sendo disponibilizados no mercado e à possibilidade de internet gratuita em praticamente todos espaços públicos. 
b) Como o sistema de leitura e escrita é a principal via de acesso ao conhecimento e de interação social, para poderem estar conectados e se sentirem participantes do mundo, os surdos reconhecem que precisam ser não apenas sinalizantes fluentes, mas também letrados, daí atribuírem importância fundamental ao conhecimento da Língua Portuguesa escrita.

c) A produção escrita dos surdos entrevistados, mesmo daqueles com curso superior e até mesmo pós-graduação ainda se apresenta repleta de equívocos, evidenciando que o avanço na escolarização não implica necessariamente em uma competência na escrita.

d) A competência na leitura e interpretação de textos indica que a informação principal é compreendida, ou seja, no caso específico todos os sujeitos compreenderam que a notícia tratava de um acidente, entretanto, os detalhes não foram compreendidos, indicando que mesmo com curso superior, a leitura ainda fica restrita a um âmbito funcional.

Dois foram os resultados que não havíamos previsto em nossas análises prévias: o de que os surdos considerariam que os recursos tecnológicos os distanciavam da Língua Portuguesa escrita e o aparente descaso com a possibilidade de aprender com softwares do tipo Word.

Para podermos inferir a resposta ao nosso problema de pesquisa, ainda temos algumas considerações metodológicas: uma referente à adoção da pesquisa qualitativa realizada em etapas e a outra referente ao fato de que toda parte da coleta das informações foi realizada pela pesquisadora surda, co-autora deste texto.

A opção por uma investigação de caráter qualitativo cujo corpus empírico se constitui de três etapas que podem, ser considerados estanques, se deu quando foram delineados os objetivos específicos que contribuiriam para alcançar o objetivo geral e constatamos que eles proporcionavam questões norteadoras específicas, cujas respostas, ao serem analisadas em conjunto, permitiria responder o nosso problema de pesquisa. Cada uma dessas etapas em separado e mesmo a investigação em sua totalidade não possibilita a generalização dos resultados, entretanto, possibilita refletir e suscitar outras questões de investigação, como, por exemplo, a naturalização com que os surdos entrevistados aceitam as limitações de suas produções escritas seria uma característica de todos os surdos? Se sim, porque? Se não, quais seriam as causas para que esses sujeitos assim reagissem? 
A opção para que todos os contatos com os entrevistados fossem feitos pela pesquisadora surda, também membro da Associação que congrega todos os entrevistados, possibilitou que as entrevistas ocorressem de maneira agradável, amigável, com a conversa fluindo naturalmente, sem que os sujeitos se sentissem "analisados" ou "avaliados" por "estranhos ao seu principal ambiente de encontro", além de que, nesta dupla condição, de pesquisador e também, sujeito em potencial, ela também observa, com o "olhar do surdo" não apenas a respostas dos entrevistados, mas se os instrumentos elaborados eram compatíveis aos sujeitos.

Apesar de resultados parciais haverem sido apresentados em eventos científicos e mesmo publicados em um periódico ao apresentarmos, neste texto, a pesquisa em sua íntegra e estabelecendo novas conclusões e inferências possibilitamos uma visão holística dos mesmos, permitindo a compreensão de todo trabalho realizado.

Consideramos que nossos resultados indicam que os surdos brasileiros, urbanos, alfabetizados e letrados utilizam a maioria dos recursos tecnológicos disponíveis, embora, nem sempre a comunicação se efetive, em função de eles possuírem um repertório lexical bastante restrito em Português. A qualidade dos conteúdos das informações trocadas, mesmo entre surdos alfabetizados aumenta em complexidade e aprofundamento, quando as mensagens são em Libras. Dito de outra forma, o conteúdo da comunicação entre surdos e entre surdos e ouvintes efetivada mediante a Língua Portuguesa escrita geralmente é contextualizado e simples, o que evidencia que o uso social da escrita não está possibilitando avanços em sua apropriação pelos surdos.

Entretanto, esse novo modelo de convívio social, que permite que as distâncias sejam minimizadas pela comunicação virtual, parece apresentar novas possibilidades para a adoção da escrita pelos surdos, a qual, sem uma ação sistematizada da escola parece não estar sendo percebida por eles. Assim, consideramos a hipótese de que esses recursos tecnológicos podem ser utilizados como motivação e como ferramentas eficazes para que o surdo alcance melhor desempenho na escrita formal do Português.

A aquisição da língua escrita exige abstração de ouvintes e surdos, dos primeiros, porque a percepção da escrita se efetiva pela visão, porém, como a percepção da língua oral é auditiva, o apoio fonológico serve de apoio à esta abstração. No caso dos surdos, mesmo sendo ambas as línguas, a de sinais e a escrita visualmente perceptivas, a escrita, por não se apoiar em imagens, exige dos surdos um esforço maior de abstração. É como se no cérebro deles existisse um "dicionário" capaz de converter a leitura para o Português oral e, em seguida, para a Libras, para então ser compreendida pelos surdos. No caso da 
escrita, o caminho é o inverso: o surdo pensa em Libras, converte seu pensamento para a Língua Portuguesa oral, para então escrever.

A escrita é distante da "fala" do cotidiano, pois na escrita formal utiliza-se a norma culta da língua. A escrita produzida com os recursos tecnológicos, particularmente com recursos interativos, é mais flexível e isso facilita a comunicação dos falantes e até mesmo dos surdos sinalizadores. Isso porque, nessas situações, não se exige o uso da norma culta da língua, tornando-a mais próxima da "fala" entre as pessoas.

\section{Conclusões}

As ferramentas tecnológicas disponíveis neste final da década de 2010 possibilitam aos surdos uma interação social como nunca foi possível antes, tornando-os cidadãos visíveis para a sociedade e autônomos na condução da própria comunicação.

A primeira etapa da investigação nos permitiu constatar que com a acessibilidade aos recursos tecnológicos, as relações familiares, sociais e mesmo profissionais dos surdos melhoraram sua qualidade. Um ponto em comum entre os sujeitos foi a afirmação sobre a importância do avanço dessas tecnologias. Na entrevista realizada nessa primeira etapa alguns dos participantes relataram que antes da década de 1990, como existia pouca acessibilidade de comunicação virtual, eles pediam à família, amigos, ou alguém ouvinte para telefonar e mandavam cartas que demoravam a chegar e, assim, demoravam a receber as respostas. Quando tinham urgência em se comunicar com os amigos surdos, a saída era ir de bicicleta, de transporte coletivo ou qualquer outro veículo para conversar pessoalmente.

De maneira geral, os surdos consideram que os recursos tecnológicos facilitaram sobremaneira a comunicação entre eles, além de possibilitar o acesso à informação sobre o que acontece no mundo com o uso da internet. A própria investigação realizada confirma esta afirmação, afinal, se as questões para as entrevistas realizadas não tivessem sido traduzidas para Libras e gravadas em vídeo, assim, como as respostas a essas questões não pudessem contar com tais recursos talvez esta investigação não fosse possível. Como registrar as respostas em Libras dos sujeitos, sem os vídeos? Ficaríamos restritos às informações escritas e como a escrita do surdo é limitada, teríamos também informações limitadas. 
Ao colocarmos, durante a realização da segunda etapa da investigação, uma "intenção educacional" 14 na utilização dos recursos tecnológicos como o Word buscando facilitar a aprendizagem da língua escrita concluímos que os surdos possuem não apenas a percepção, mas a consciência dos equívocos que cometeram ao redigir um manuscrito. Perceberam também a limitação que a escrita lhes impõem, o que ficou evidente, por exemplo, quando comparamos a história de vida de Cristina, expressa por ela em seu texto manuscrito e a que foi relatada em Libras. Entretanto, mais até por não estarem interessados em corrigir seus erros, para eles a utilização apenas social da Língua Portuguesa é suficiente e assim, a comunicação mesmo repleta de equívocos e limitada os satisfaz.

Para os surdos participantes da pesquisa o fundamental é se fazerem entender, e isto ocorre, mesmo com os equívocos cometidos em sua escrita. A intenção de se fazer entender se sobrepõe ao esforço para dominar o português escrito, a despeito dos resultados da primeira etapa ter demonstrado a unanimidade entre os entrevistados de que conhecer a Língua Portuguesa na modalidade escrita é fundamental para os surdos.

Desta forma, todos reconhecem a importância deste conhecimento, possuem consciência das dificuldades em produzir textos, porém, nem todos têm clareza das próprias limitações na interpretação de textos. Isto ficou evidente na realização da terceira etapa com as dificuldades apresentadas pelos surdos em compreender a notícia e, principalmente, em serem fiéis ao que estavam lendo.

Aqui merece uma menção à cultura surda. Enquanto no meio ouvinte dificilmente pessoas iletradas e cultas convivem intensamente no meio social, com exceção das relações familiares, esta situação é bastante comum entre os surdos, fora do contexto escolar e familiar, sem que o fato de ser iletrado em Língua Portuguesa se constitua em fator de exclusão social ou de preconceito na comunidade surda. Portanto, a comunicação entre surdos letrados e iletrados é uma constante, razão pela qual a utilização do recurso "vídeo" seja praticamente indispensável para essa comunidade.

Nossa investigação mostrou ainda que, embora todos os sujeitos colaboradores fossem educados na perspectiva oralista, e, portanto, com ênfase na aprendizagem da Língua Portuguesa, apresentaram dificuldades na produção e na interpretação de textos. Então, conjecturamos se com a possibilidade da comunicação virtual em Libras, afinal os

\footnotetext{
${ }^{14}$ Por "intenção educacional" consideramos a possibilidade do software colaborar com a aprendizagem da língua escrita ao mostrar os equívocos cometidos.
} 
próprios sujeitos afirmaram que com a possibilidade da comunicação à distância em Libras, cada vez mais se restringe o uso social do Português escrito e com a adoção da abordagem bilíngue, com suas respectivas conquistas, como o direito ao intérprete, particularmente o intérprete educacional; os critérios diferenciados para a correção de questões discursivas ou produções textuais podem minimizar os esforços dos estudantes surdos e da própria escola no ensino da escrita e da leitura e assim, pesquisas como esta, se realizada futuramente não apontariam para maiores dificuldades dos surdos com a Língua Portuguesa.

Não estamos aqui desconsiderando a importância dessas conquistas, o que propomos é que, uma vez tendo o surdo adquirido sua primeira língua, a Libras, que o ensino da Língua Portuguesa escrita constitua parte integrante e prioritária nos currículos das escolas inclusivas e bilíngues, ou seja, que os surdos tenham acesso a um currículo adaptado que contemple este estudo.

As novas tecnologias podem representar, para alguns surdos uma ressignificação do sentido social da escrita do português, mesmo nem todos os surdos estando preocupados com essa relação. Mas, seguramente, ao ampliar as possibilidades comunicativas, pelo uso de vídeos, imagens e também da escrita, as tecnologias de informação revolucionaram o universo social de sujeitos surdos conferindo-lhes uma vida mais autônoma.

Desta forma, todos reconheceram a importância do conhecimento da Língua Portuguesa escrita, mas nem todos tiveram clareza das limitações de suas produções textuais e não perceberam o potencial das ferramentas digitais para minimizá-las. Limitações estas que foram constatadas na produção de textos. Cabe à escola aproximar os surdos das possibilidades dos recursos tecnológicos para a aprendizagem da Língua Portuguesa escrita.

\section{Referências}

BRASIL. Política Nacional de Educação Especial, Brasília, DF, 1994.

Brasil. Lei federal $\mathbf{n}^{\mathbf{0}}$ 10436, de 24 de Abril de 2002. Dispõe sobre a Língua Brasileira de Sinais - Libras e dá outras providências, 2002.

CARNEIRO, M. I. N. O uso social das tecnologias de comunicação pelo surdo: limites e possibilidades para o desenvolvimento da linguagem. 2016. 200f. Dissertação. (Mestrado em Educação) - Universidade Estadual de Maringá, Maringá, 2016. 
CARNEIRO, M. I. N.; SILVA, T. S. A. da.; NOGUEIRA, C. I. Uso Social da Língua Portuguesa Escrita pelo surdo: competência na interpretação de uma notícia. Imagens da Educação, Maringá, v. 7, n. 3, p. 13-25, 2017.

CARNEIRO, M. I. N.; NOGUEIRA, C.M.I; SILVA, T.S.A. Recursos tecnológicos nas interações cotidianas de adultos surdos. In: IV CONGRESSO INTERNACIONAL DE EDUCAÇÃO E TECNOLOGIA E ENCONTRO DE PESQUISADORES EM EDUCAÇÃO A DISTÂNCIA, IV CiET: ENPED, 2018, São Carlos. Anais... São Carlos: UFSCAR, 2018. s.p.

CARNEIRO, M. I. N.; NOGUEIRA, C.M.I; SILVA, T.S.A. CARNEIRO, M. I. N. A importância da língua portuguesa escrita nas interações cotidianas de adultos surdos. In: SEMINÁRIO INTERNACIONAL DE PESQUISAS E ESTUDOS QUALITATIVOS, 5, 2018, Foz do Iguaçu. Anais... Foz do Iguaçu, Cascavel: UNIOESTE, 2018. s.p.

CÔNSOLO, A. T. A tecnologia na comunicação entre surdos: Efeitos do computador, da internet e do celular na comunicação escrita entre surdos. 1. ed. São Paulo: Novas Edições, 2014.

FERNANDES, S. Letramentos na Educação Bilíngue para Surdos. In: BERBERIAN, A. P.; MORI-DE-ANGELIS, C. C.; MASSI, G. (Orgs.). Letramento: Referências em saúde e Educação. 1. ed. São Paulo: Plexus, 2006. p. 117-144.

GOETTERT, N. Tecnologias Digitais e Estratégias Comunicacional de Surdos: da vitalidade da Língua de Sinais à necessidade da Língua Escrita. 2014. 164 f. Dissertação (Mestrado em Educação) - Universidade do Vale do Rio dos Sinos, São Leopoldo, 2014.

NOGUEIRA, C.M.I; SILVA, T.S.A. A percepção de surdos acerca dos equívocos cometidos em suas produções escritas In: CONGRESSO BRASILEIRO DE EDUCAÇÃO, 8, 2018, São Carlos. Anais... São Carlos: UFSCAR, 2018.

Recebido em: 10 de setembro de 2018 .

Aceito em: 07 de dezembro de 2018. 